\title{
Corporate Governance: Is It Time For Global Standards?
}

\author{
Peter A. Stanwick, (Email: pstanwick@business.auburn.edu), Auburn University
}

\begin{abstract}
Financial markets depend on the integrity of the financial information generated by management. In order for that integrity to be ensured, an effective corporate governance system must be in place by the corporation. While the United States has been the initial focal point on the effectiveness of corporate governance through the actions at Enron and WorldCom, European companies such as Ahold, Parmalat and Adecco have also demonstrated that the European Union faces challenges pertaining to corporate governance. The purpose of this paper is to compare how the United States and the European Union address the issue of corporate governance. The paper will examine and compare the Sarbanes-Oxley Act in the United States, the European Commission's Action Plan on corporate governance and the new corporate governance guidelines issues by the Organization for Economic Cooperation and Development. The paper will conclude with a discussion on whether global corporate governance standards are necessary to ensure the stability of global financial markets. The author will argue that certain core standards are universal in nature. However, flexibility is still warranted in some areas due to specific cultural beliefs and established business standards.
\end{abstract}

\section{INTRODUCTION}

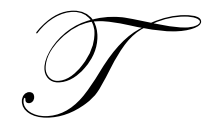

he corporate scandals that have impacted companies headquartered in both the United States and in other parts of the world has lead to a re-examination of the role of corporate governance in the day to day operations of the firm. The purpose of this paper is to examine how corporate governance is approached from three independent, but, related perspectives. The paper will examine three corporate governance frameworks: the United States' Sarbanes-Oxley Act, the European Commission's Action Plan and the Organizational for Economic Cooperation and Development (OECD)'s Corporate Governance Framework. The paper will conclude with recommendations on how the integration of these different frameworks can be accomplished when corporate governance frameworks are developed in the future.

\section{Benefits Of Good Corporate Governance}

If a company has implemented a positive corporate governance framework, it allows the firm to not only to more effectively allocate their resources in their decision making process, but, it also increases the level of confidence in the financial markets of the accuracy and transparency of their information. It also allows the firms to be able to develop more viable strategic objectives by having accurate information. The implementation of a good corporate governance framework also allows the shareholders to feel confident about their investment decisions. It can also yield financial benefits for the firm by reducing the cost of capital and by generating higher levels of efficiencies for the firm's resources through higher investor confidence. A strong corporate governance framework also can be used to complement the overall check and balance system used to monitor the operations of the firm.

By having good corporate governance implemented at a national level, global investors will pay a premium for investment opportunities in that country. As a result, strong corporate governance can lead to an increased level of stability in the financial markets and make it easier for the country to attract additional financial investments. Furthermore, a good corporate governance framework allows for a clearly defined relationship between the shareholders, the firm and other stakeholders. 


\section{An Example Of Different Governance Philosophies}

CEO Compensation continues to be a controversial subject on both sides of the Atlantic ocean. However, how United Kingdom shareholders and United States shareholders view their participation in the discussion is different. In the United States, it appears to be the responsibility of the institutional investors to raise any objections about the level of compensation given to the CEO and other members of the top management team. Alternately, shareholders in the United Kingdom routinely vote on executive compensation packages and will reduce the payments given if they deem them to be excessive (Eisinger, 2006). In addition, for United Kingdom firms, there is usually not the potential governance issue of CEO duality. CEO duality occurs when the CEO is also the chairman of the board. This concentration of power could potentially threaten the check and balance system of the board of directors. In the United Kingdom, very few large firms have a CEO who is also the chairman of the board. However, in the United States, CEO duality is a very common practice among large firms.

\section{The United States' Sarbanes-Oxley Act (Sox)}

In direct response to the corporate scandals of Enron and WorldCom, the Unites States Congress passed the Sarbanes-Oxley Act in 2002. When it passed in 2002, many corporations were vocally opposed to it and claimed that is was just an additional set of government regulations that would cost additional time and money which they could not afford in an increasingly competitive global marketplace. However, by 2004, the viewpoint had changed significantly for a majority of firms. In a 2003 survey of 153 board of directors members by Corporate Board Member magazine ${ }^{1}$, sixty percent of those surveyed thought the Sarbanes-Oxley Act had a positive effect on the firms. In addition, seventy percent of the directors thought that the Sarbanes-Oxley Act had a positive effect on the activities of board of directors actions.

\section{Highlights Of The Sarbanes-Oxley Act}

There are a number of provisions in the Sarbanes-Oxley Act that have both an immediate and long term impact on how firms are monitored in the United States. Each publicly traded firm must be accountable to a government appointed Public Company Oversight Board which is comprised of 5 members who are "financially literate". Of the 5 members of the oversight board, two members must be Certified Public Accountants (CPAs). The oversight board creates and approves the guidelines used by external auditors in their review of financial information pertaining to the firm.

The Sarbanes-Oxley Act also requires that the external (independent) auditors who review the financial statements of the firms are restricted to performing audit based functions. Contrary to what was acceptable in the past, external auditors are not allowed to perform bookkeeping functions, nor are they allowed to do non-audit based consulting. The firm's audit committee must pre-approve all the services provided by the external auditors. In addition, the lead audit partner and the partner responsible for the audit must change at least once every 5 years for the same client. One of the most critical components of the Sarbanes-Oxley Act was the requirement that both the firm's CEO and CFO must certify all annual and quarterly reports sent to the Securities and Exchange Commission (SEC). This was a significant change in the past policy of the SEC. Based on the certification process by the CEO and $\mathrm{CFO}$, the CEO no longer can plead ignorance as a defense for inaccurate financial statements. This provision states that the CEO and CFO are guilty of fraud if they certify inaccurate financial results regardless on whether they knew the results were false or not. In addition, the CEO and the CFO are required to forfeit any financial gain that has occurred through bonuses and/or profits based on inaccurate financial results. In addition, all of the board members and the top executives of the firm must report to the SEC all stock transactions within two business days. It is also the fiduciary duty of the firm's lawyers to report to the board of directors any violations of securities fraud. Another common practice which was now banned by the Sarbanes-Oxley Act is the issuing of personal loans to any director or top executive by the firm.

\footnotetext{
${ }^{1}$ Norton, Rob. “Living With An 800-Pound Law” Corporate Board Member May/June 2004.
} 
From a reporting perspective, the Sarbanes-Oxley Act requires that every publicly traded company must include in its annual report a description of the firm's internal controls. Although not explicitly stated, the requirement has been interpreted to mean not only financial controls, but also operational and information technology controls. In addition, an external auditor must review the internal control procedures of the firm. It is also a requirement that each firm must develop and make available a corporate code of ethics which has to be at least applicable to the firm's top executives.

In addition, firms are required to hold separate directors meetings where the CEO is not present. This allows for a more explicit separation of the influence the CEO has on the agenda and the direction of the board meetings. In direct response to Enron's manipulation of financial statements, the Act requires the firm to report, in detail, all off-balance sheet transactions.

The Sarbanes-Oxley Act has also significantly increased the severity of the penalties for managers if they are found in violation of the Act. Any employee of the company can receive a prison sentence of up to 20 years if they are found guilty of destroying, altering and/or falsifying any financial or audit information. In addition, an employee can receive up to 25 years in prison if they are found guilty of knowingly defrauding any investors based on the actions or the information given by the employee.

Furthermore, it is a violation of the Act for a company to penalize an employee who is whistle blower by suspending, harassing or threatening the employee for their actions. This is the first time that strict guidelines have been set to explain what is not acceptable by the firm pertaining to the treatment of the whistleblower. One underlying question is whether the Sarbanes-Oxley Act will be good or bad for business in the United States and around the world. Michael Cook, the CEO emeritus and retired Chairman of the Board of Deloitte and Touche and Board member of Comcast Cable, Dow Chemical, Fidelity Investments, International Flavors and Fragrances, and Northrop Grumman states that "Overall, you have to say it has had a good effect. Sarbanes-Oxley got people focused on financial reporting and quality, and concerned with the consequences of not getting it right."

\section{The Impact Of The Sarbanes-Oxley Act}

Based on the more stringent reporting requirements of the Sarbanes-Oxley Act, the number of restatements of financial results increased significantly from less than 250 companies in 2000 to almost 1,200 companies in 2005 (Reilly, 2006). In their report to their investing clients, Glass Lewis and Company stated that "Over time, as companies continue to improve their internal controls, we expect the number of restatements eventually will decline, perhaps as soon as 2006." ${ }^{33}$ Foreign based companies that do business in the United States also have felt the impact for SOX. The number of non U. S. companies that had to make restatements rose from 37 in 2004 to 100 in 2005. The U. S. reporting requirements for foreign based companies has raised concerns about whether non U. S. companies would want to list on an American stock exchange because of the SOX requirements. It has been estimated that approximately 90 percent of non U. S. based firms would not go public in the United States due to the increased level of government regulations (Greifeld, 2006).

Another concern was the impact SOX would have on smaller firms that could not "afford" the additional cost of SOX compliance. However a recent survey in The Wall Street Journal found that the compliance costs were decreasing for smaller firms over time. A survey of 66 firms with market capitalization from $\$ 75$ to $\$ 700$ million found that their compliance costs were decreasing. The amount of fees paid to outside suppliers had decreased from $\$ 463,000$ in 2004 to $\$ 223,000$ in 2005 . The costs of internal company controls had dropped from $\$ 355,000$ in 2004 to $\$ 301,000$ in 2005 . The cost of internal controls and fees had been reduced from $\$ 423,000$ to $\$ 336,000$. The only major compliance category to increase in costs was general audit fees which went from $\$ 423,000$ in 2004 to $\$ 477,000$ in 2005 (Reilly, 2006a).

\footnotetext{
${ }^{2}$ Norton, Rob. "Living With An 800-Pound Law" Corporate Board Member May/June 2004.

${ }^{3}$ Reilly, David. Sarbanes-Oxley Changes Take Root. The Wall Street Journal. March 3, 2006.
} 


\section{European Commission Action Plan}

In February 2000, the President of the Commission to the European Parliament, Romano Prodi, stated that the establishment of new governance requirements is one of the critical objectives of the Commission. In 2001, the European Commission presented the White Paper on European Governance which was available on the internet for public comment. In 2002, the framework for the European Commission's Action Plan was established.

The European Commission's Action Plan is separated into three different time horizons: short term (20032005), medium term (2006-2008) and long term (2009 and beyond).

\section{SHORT TERM REQUIREMENT OF THE EUROPEAN COMMISSION ACTION PLAN}

In the short term, firms that are members of the European Union are required to explain in their annual report their current corporate governance structure. The explanation needs to address such factors as: shareholder rights, composition and operation of the Board of Directors, the identification of major shareholders and their voting and/or controlling rights, and any material transactions between the major shareholders and any other related parties of the firm.

An additional requirement related to shareholder rights is the responsibility of the firm to ensure that shareholders are able to exercise their rights fairly and without intimidation. In addition, firms are required to allow shareholders the ability to ask the firm questions in any appropriate forum, allow the shareholders to vote in absentia and allow the shareholders to participate in general shareholder meeting electronically.

An additional short term element of the European Commission's Action Plan is to have more independent board members with specific emphasis on compensation and the audit committee. In addition, the firm must establish minimum standards for the development and the responsibilities of the nomination, remuneration and audit committees that are consistent the European Union standards.

As with the Sarbanes-Oxley Act, the European Commission's Action Plan requires that the Board of Directors be collectively responsible for the firm's financial statements. In addition, each publicly traded firm must disclosure the firm's compensation policy and each director's level and the composition of their total compensation must be easily attainable and transparent.

The European Commission's Action Plan also recommends in the short term, the establishment of a European Corporate Governance Forum which could be used to aid in the co-ordination of corporate governance guidelines across the European Union members.

In the Medium term, the European Commission's Action Plan recommends that firms be required to present to the shareholders the investment and voting policies of the major institutional investors. In addition, the European Commission Action Plan allows the firms to decide which type of Board of Directors structure they want to implement. They can have either a single (monistic) or two tiered (dualistic) board structure. The two tiered board structure is designed so that one level of the Board of Directors is involved in operational and day to day decisions of the firm and includes employee membership.

The other level of the board controls the overall decision making of the firm and would include membership of the firm's top executives including the CEO. The third component of the medium term elements of the European Commission's Action Plan is to give shareholders the right to investigate the actions of the firm if the shareholders believe that inappropriate and /or illegal activities have occurred within the firm.

At this point, the European Commission's Action Plan has not established specific long term objectives. It is the belief of the Commission that an evaluation of the implementation of the short term and medium objectives must first be accomplished before the establishment of long term objectives can take place. 


\section{OECD's Principles Of Corporate Governance Framework}

In 2004, the Organization for Economic Cooperation and Development (OECD) revised the original principles of Corporate Governance that were established in 1999. Countries from all over the world have membership in the OECD. Countries that have a current membership in OECD include the founding members of: Austria, Belgium, Canada, Denmark, France, Germany, Greece, Iceland, Italy, Luxembourg, the Netherlands, Norway, Portugal, Spain, Sweden, Switzerland, Turkey, United Kingdom and the United States. Additional members of the OECD include: Japan, Finland, Australia, New Zealand, Mexico, Czech Republic, Hungary, Poland, Korea and the Slovak Republic. The OCED's Principles of Corporate Governance include the requirement that the framework of the country adopting the principles should have transparency and encourage efficient markets. In addition, the framework of member countries should support the laws of the local government and the framework needs to identify the specific responsibilities of the firm's managers.

Furthermore, any framework established by an OECD member should protect and support the rights of the firm's shareholders. It is also imperative that the corporate governance framework should support the fair treatment of each individual shareholder. It is expected that included within the fair treatment are factors such as: all shares carry the same voting rights and all investors should have access to the same information. The framework should ensure that insider trading is not available or implemented. In addition, the framework should include the requirement that every board member needs to disclose any potential conflicts of interest. It is also proposed by the OECD that any corporate governance framework established by a member should encourage co-operation between the firm and the shareholder to encourage shared wealth. It is expected that strong co-operation between the firm and the shareholder would allow for the development of new jobs and the ability to ensure long-term financial sustainability.

In addition, the corporate governance framework should allow the shareholders the opportunity to correct any direct or indirect violations of their rights. Furthermore, the framework needs to have a performance-enhancing system in place to encourage employee participation. The framework should allow any shareholder the right to present their concerns about illegal or unethical activity without any constraints.

The framework adopted by the OECD member should ensure timely and accurate disclosures of relevant information pertaining to the firm. The firm must also disclose complete financial results and the overall objectives of the firm. In addition, the framework must also require the firm to disclose: the compensation policy for top executives and board members, the potential risk issues the firm currently faces or anticipates may occur in the future, the detailed results of the firm's external audit and the verification by the firm that the information that is released is based on formal accounting standards.

The OECD recommends that every member's corporate governance framework should incorporate the Board of Directors strategic focus in their disclosures. This would include, but not be limited to, the review of the monitoring and the decision making activities of the firm's management. The framework must explicitly state that the Board of Directors is directly accountable to the firm and its shareholders. The Board of Directors are also responsible for ensuring that the firm has established and implemented a training program to support high ethical standards within the firm. It is also expected that within the OECD member's corporate governance framework that a detailed process outlining the selection and the compensation and evaluation of the Board of Directors is disclosed to shareholders. The Board of Directors is ultimately responsible for ensuring the integrity of the financial information disclosed by the firm. The Board of Directors also needs to have a "sufficient" number of independent board members who are not executives of the firm.

\section{Where Do We Go From Here?}

Based on the summary of three related, but, different approaches to corporate governance, the question remains what should be done now? One question that needs to be addressed is whether global corporate governance standards are a viable option. As has been shown in the areas of law and accounting, having global standards would 
create more challenges than it resolves. As is the case with any rules or procedures, the unique differences between countries and cultures must be acknowledged when establishing any type of framework.

The inherent problem of trying to establish and implement global corporate governance standards is the fundamental difference in how different countries view the relationship between the government, the firm and the shareholder. The demands of the shareholders and other stakeholders makes reconciliation of these global differences impossible to manage. However, an alternative view should be to embrace the differences and learn from them. One lesson to be learned is that that there are viable alternative approaches on how to view corporate governance from a global perspective.

There are three fundamental areas in which the Sarbanes-Oxley Act, the European Union Commission and the OECD framework have in common. Those three areas are: the controlling and/or monitoring of board members' actions, the identification of the responsibility of the board members individually and collectively, and the duties board members have to stakeholders. As a result, different countries can learn by observing each other's actions on how to develop and fine tune their corporate governance structure. For example, the European Union Commission allows and encourages the EU members to consider both a single and dual board relationship. Although not likely in the short term, this seems like a viable option that should be considered by United States based firms. The SarbanesOxley Act has already informally created a second government based board level with an establishment of a Public Oversight Board that reviews some of the firm's operations. Therefore, it may not be that large of a "step" for US firms to establish a two tier board system.

One common thread that has been woven among the three different perspectives is to establish better guidelines on how to select board members and the CEO. As all three perspectives emphasize, any effective corporate governance framework must be agreed upon and supported by the board and the CEO. As a result, the selection process is critical and a linchpin for every other part of the framework. It is also stressed that within the selection process, an evaluation of previous behavior by the board members may allow the firm to predict whether the new board members will support the current corporate governance framework. Furthermore, regardless of the perspective, it is commonly agreed that every firm should include explicit guidance into what is considered to be acceptable and unacceptable conduct with a detailed explanation of the punishment and recourse if unacceptable behavior is identified by the board members.

One of the glaring omissions from the three perspectives is the lack of explicitly stating their case as to why the strong corporate governance framework is a positive factor for each firm. Within the United States, firms are complaining that the Sarbanes-Oxley Act only adds "costs" and time to their operations without any real benefit. It is up to the United States Government, the European Union and the OECD to explain the benefits of these frameworks. The CEO and the Board of Directors should view internal controls and monitoring as an opportunity and not merely a cost of doing business. By spending billions of dollars on information technology, operations, manufacturing, research and development, it would seem to be a benefit to the firm to have an explicit monitoring system in place to ensure the most efficient use of their resources.

Another overlapping recommendation is to have a disproportional number of truly outside board members on the overall board and the critical sub committees, including the compensation and auditing committee. "Truly" outside members are those board members do not have either direct or indirect financial ties with the firm. An example of an indirect tie would be interlocking directorates. An interlocking directorate is when a board member will sit on a firm's board and an executive from that firm will sit on the board member's own Board. In other words, the board members sit on each other boards so that even though they may be considered technically outside members, they are for all practical purposes inside board members.

The benefit of having "truly" outside board members is that is allows alternative viewpoints to be presented and allows for a more objective evaluation of the firm's strategy and a more objective evaluation of the firm's operations. In addition, it allows for more equitable decision making pertaining to the firm's compensation and auditing policies. 
In summary, the implementation of a strong corporate governance framework should be considered an opportunity and not an additional cost for the firm. The firm has the opportunity to re-evaluate and improve its relationship with its various stakeholders, including the firm's customers, employees, suppliers and other stakeholders.

\section{BIBLIOGRAPHY}

1. AICPA. 2004. Summary of Sarbanes-Oxley Act of 2002. www.aicpa.org/

2. Commission of the European Communities. 2003. Modernizing Company Law and Enhancing Corporate Governance in the European Union-A Plan to Move Forward. Communication From the Commission to the Council and the European Parliament

3. Commission of the European Communities. 2003. Report from the Commission on European Governance. Luxembourg: Office for Official Publications of the European Communities.

4. De Azambuja, M. 2000. Corporate Governance in Latin America: New Thoughts For A New Century. The Latin American Corporate Governance Roundtable. P. 1-5

5. $\quad$ Eisinger, J. 2006. No Excessive Pay, We're British. The Wall Street Journal. February 8, 2006.

6. $\quad$ Greifeld, B. 2006. It's Time To Pull Up Our SOX. The Wall Street Journal. March 6, 2006.

7. Ocampo, R. 2000. Corporate Ownership and Corporate Governance: Issues and Concerns in the Philippines. Asian Center for Corporate Social Responsibility p. 1-7.

8. OCED Principles of Corporate Governance. www.oecd.org/daf/corporate-affairs

9. Myers, Randy. 2003. Sarbanes-Oxley's Audit Committee Deadline Sparks Fear, Loathing. Corporate Board Member: What Directors Think: Special Issue p. 1-2

10. Norton, R. 2004. Living With An 800-Pound Law Corporate Board Member May/June. P. 1-10.

11. Reilly, D. 2006. Sarbanes-Oxley Changes Take Root. The Wall Street Journal. March 3, 2006.

12. Reilly, D. 2006a. Internal-Control Help Becomes Less Costly. The Wall Street Journal. April 19, 2006.

13. Sarbanes-Oxley Act of 2002. www.findlaw.com

14. Sarbanes-Oxley Act of 2002. www.sarbanes-oxley.com

15. Sarbanes-Oxley Act of 2002 www.sec.gov

\section{NOTES}


NOTES 